\title{
A CASE OF GASTRIC CARCINOMA WITH SPONTANEOUS GASTRO-JEJUNOSTOMY
}

\author{
By C. C. Gardner, M.B., Ch.B., F.R.C.S.(E.) \\ Senior Lecturer in Surgery; University College of the West Indies
}

Direct extragastric spread of carcinoma of the stomach to the liver, pancreas or anterior abdominal wall is familiar; and spread to the transverse colon with formation of a gastrocolic fistula is not excessively rare. Perforation of the stomach wall into the peritoneal cavity has been reviewed by Aird (1935) and further cases are reported by Feldman and Weinberg (1950).

The following case, however, differes in that the first clinically significant extragastric spread was to the jejunum and duodeno-jejunal flexure.

\section{Case Report}

C. M., negro male, aged 60 years, attended the University College Hospital of the West Indies on July 24, 1953. For two months he had been complaining of great weakness, constipation and upper abdominal pain constantly present but aggravated by the ingestion of food. During this time he had been vomiting once or twice daily, and the vomiting relieved the pain. He showed severe cachexia and had a hypochromic anaemia with $4.5 \mathrm{gm}$. of haemoglobin per $100 \mathrm{ml}$. of blood. No palpable tumour could be detected in the abdomen, nor any distension or evidence of free fluid. Rectal examination revealed no significant abnormality.

A barium meal X-ray examination on July 30 , I953 (Fig. I), was reported upon as follows (Dr. W. R. Cole):

Stomach. The stomach contained food material and showed considerable deformity of the antrum, with the contraction of the lesser curve drawing the antrum up. This area was tender on pressure. Peristalsis was poor.

Duodenum. The cap was not well seen on the screen, but, in the prone film appears to have filled beyond the deformed area.

Conclusion. The appearances suggest old ulceration of the lesser curve, with deformity and delay in emptying. Malignant change in this area cannot be excluded.

He was admitted to hospital on August 17, i953. Operation was delayed because of the

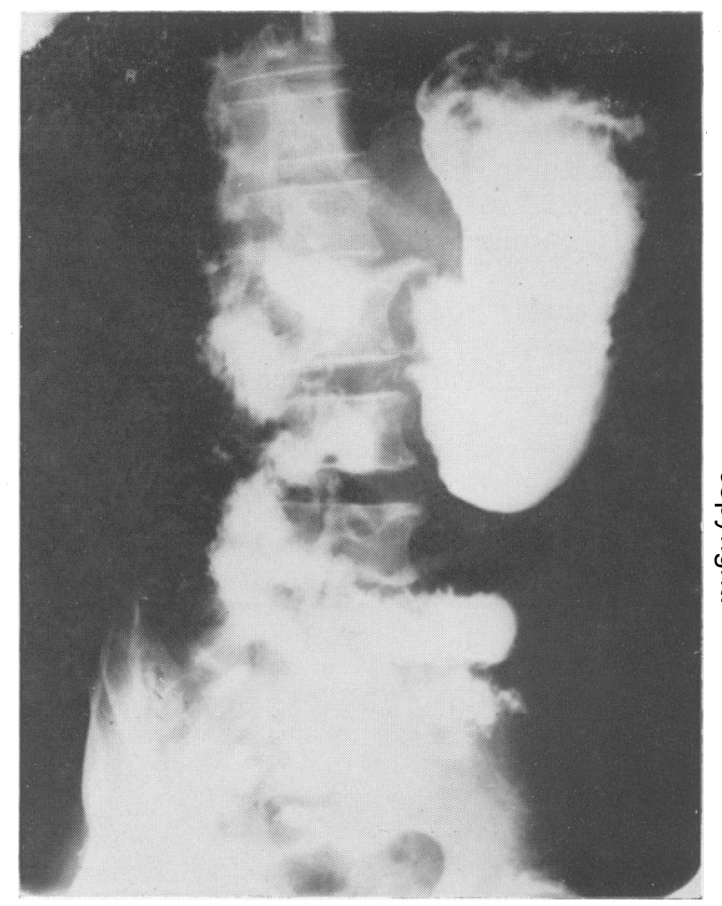

FIG. 1.-Barium meal, July 30, 1953, showing deformity of the pyloric antrum.

patient's anaemia and poor general condition; these were treated with repeated blood transfusions and a high protein intake. During this time only occasional vomiting occurred, and the significance of the history of vomiting was, therefore, to some extent discounted. A mass was now palpable in the left half of the epigastrium.

Gastroscopy on September 5 showed no gross abnormality proximal to the angulus of the stomach, but a clear view of the pyloric canal could not be obtained.

Laparotomy on September 16 showed free peritoneal fluid. The whole of the pyloric antrum and canal were encircled by a solid neoplastic mass which was adherent to the left lobe of the 
liver anteriorly and to the transverse colon anteroinferiorly. Proximal to the angulus, the stomach was dilated. On the postero-inferior aspect, the growth was found to have spread across the lesser sac of the peritoneum to involve the pancreas, and through the transverse mesocolon to involve the wall of what was thought to be the most proximal loop of jejunum. At this point a gastrojejunal anastomotic fistula could be demonstrated by palpation. The stoma admitted three finger tips, and its edges were rigid and nodular as of carcinomatous tissue. The condition was judged inoperable and no better palliative measure could be devised than this naturally occurring gastroenterostomy. An omental lumph gland was taken for section and later showed adeno-carcinoma. (Dr. K. P. Clearkin.)

Recovery from the operation was uneventful and a further barium X-ray examination was carried out on October 6 (Fig. 2). Dr. Cole reported as follows:

Stomach. The mass involving the pyloric antrum was not clearly seen and the barium passed through the pathological gastroenterostomy, little or none passing into the duodenum. The wall of the distal half of the stomach was irregular and showed a constant deformity suggesting neoplastic spread proximal to the gastro-jejunostomy site. Peristalsis was absent.

Conclusion. Neoplasm of the stomach with gastro-jejunostomy fistula through which most of the stomach contents pass.

At gastroscopy on October io a satisfactory view was obtained of the stomach as far as the angulus. Gastric motility was poor and there was evidence of atrophic gastritis. A large pool of greenish-brown fluid filled the antrum; this was thought to be jejunogastric reflux which thus concealed the gastro-jejunal stoma.

During the 28 days between the laparotomy and his discharge from hospital the patient vomited small amounts on five occasions. He was discharged on October I3, 1953 .

On November 17, I953, he was readmitted. Since his discharge he had not vomited at all, and it was therefore assumed that his gastro-jejunostomy was functioning. His condition did not warrant further radiographic or gastroscopic investigation.

Three days after readmission he began to pass frequent small stools of yellow fluid, resembling the milk drinks and egg flips which were at that time the only food he could ingest. This was taken to be evidence of a gastrocolic fistula. The patient died on November 26, 1953.

Post-mortem examination (Dr. G. Bras): A generalized tibrino-purulent peritonitis had resulted from a perforation of the transverse colon

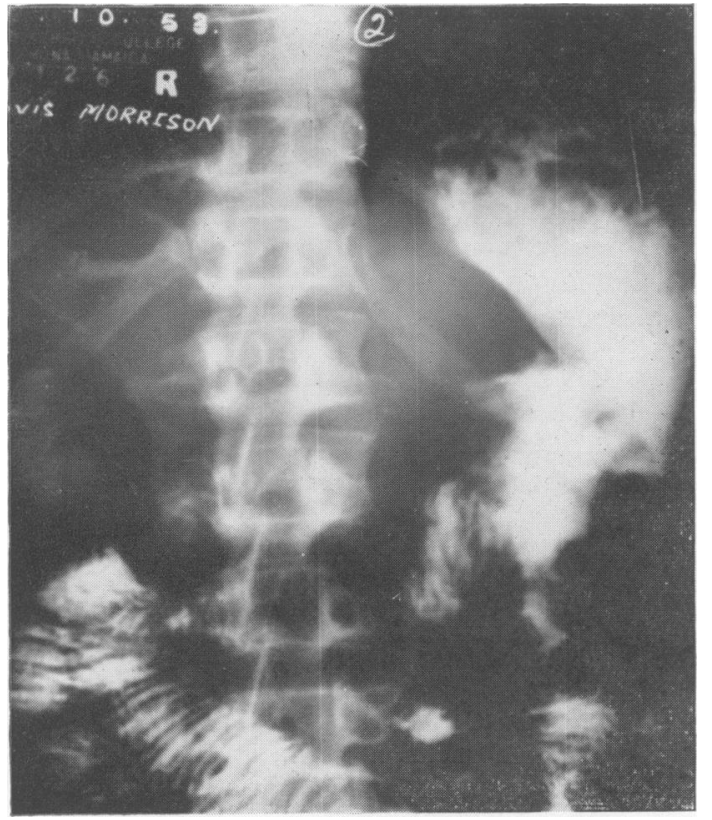

FIG. 2.-Barium meal, October 6, 1953, showing pathological gastro-jejunostomy.

on its anterior aspect. The whole of the dista. half of the stomach was occupied by carcinom? and no pyloric lumen remained. The liver and the head of the pancreas were invaded by direct spread and there were metastases in the suprapyloric and infrapyloric lymph glands. Some $\stackrel{\mathbb{Q}}{\varrho}$ glandular metastases were invading the wall of $\overrightarrow{\overrightarrow{0}}$ the common bile duct. There were no intra- 3 hepatic metastases.

There was a wide fistulous connection between the stomach and the superior aspect of duodeno- $\overline{0}$ jejunal flexure, and also, immediately anteriorly, a slightly smaller fistula leading into the transverse colon. The perforation into the peritoneal cavity was on the anterior aspect of the transverse $ᄋ$ colon at the margin of the gastro-jejunocolic fistula. $₹$ There was a wide fistulous connection between the 을 stomach, duodenum, jejunum, transverse colon, $D$ and also the peritoneal cavity in this region.

\section{Comment}

This patient died of carcinomatosis of the upper $N$ abdomen, with generalized peritonitis from per- $\underset{\omega}{N}$ foration of the transverse colon into the general peritoneal cavity. Involvement of the jejunal wallo in such advanced disease does occur, but no report $\varnothing$ of a spontaneous gastro-jejunostomy from this $\stackrel{?}{+}$ cause has been traced.

Spontaneous gastro-jejunostomy drainage of the $\frac{\vec{D}}{\mathbb{D}}$ stomach by reducing the frequency of vomiting $\frac{\stackrel{\rho}{\oplus}}{\Phi}$ 
and relieving pyloric obstruction, diminished the patient's distress for the short period of his illness.

\section{Summary}

I. A case has been described in which a primary carcinoma of the stomach spread directly to the liver, pancreas, jejunum and transverse colon.

2. Attention has been drawn to the occurrence of a spontaneous gastro-jejunal fistula, and to changes in the clinical progress of the case thought to result from this.

\section{Acknowledgments}

I should like to thank Professor G. H. C. Ovens, O.B.E., for permission to publish this case.

\section{BIBLIOGRAPHY}

AIRD, I. (1935), Brit. F. Surg., 22, 545. (1950), Gastroenterology, 15, 696 .

\section{PULMONARY TUBERCULOSIS}

\section{(Postgraduate Medical Journal)}

Price : 3s. 8d., post free

INTRODUCTORY

Maurice Davidson, D.M., F.R.C.P.

THE GENERAL MANAGEMENT OF THE PHTHISICAL PATIENT FROM THE PHYSICIAN'S STANDPOINT

L. E. Houghton, M.D.

THE PRESENT POSITION OF CHEMOTHERAPY IN TUBERCULOSIS

John C. Roberts, M.D., M.R.C.P.

THE PROBLEM OF TUBERCULOSIS IN CHILDHOOD

A. Margaret Macpherson, M.D., F.R.C.P.
COLLAPSE THERAPY (MEDICAL) IN

PULMONARY TUBERCULOSIS

F. H. Scadding, M.D., M.R.C.P.

SURGICAL COLLAPSE THERAPY IN

PULMONARY TUBERCULOSIS

J. R. Belcher.

RESECTION FOR PULMONARY

TUBERCULOSIS

W. P. Cleland, M.R.C.P., F.R.C.S.

MODERN METHODS OF DIAGNOSIS IN

PULMONARY TUBERCULOSIS:

CLINICAL, BACTERIOLOGICAL AND

RADIOLOGICAL

J. R. Bignall, M.D., M.R.C.P.

Published by

THE FELLOWSHIP OF POSTGRADUATE MEDICINE

60, Portland Place, London, W.1

\section{H. K. LEWIS \& Co. Ltd.}

Medical Publishers

and Booksellers

\section{GOWER STREET}

LONDON, W.C. 1

(Adjoining University College and Hospital)

Telephone: EUSton 4282 (7 lines)

Telegrams: Publicavit, Westcent, London

Estoblished 1844
Medical Lending Library

ANNUAL SUBSCRIPTION frOm TWENTY-FIVE SHILLINGS

Prospectus post free on application

Bi-monthly List of New Books and New Editions added to the Library sent post free on request

The Library Catalogue revised to December, 1949, containing a classified index of authors and subjects.

To subscribers 17/6 net; To non-subscribers 35/- net. Postage 1/6 Supplement 1950 to 1952 . To subscribers $3 /-$ net; to nonsubscribers $6 /-$ net; postage $6 \mathrm{~d}$.

NEW BOOKS ADDED IMMEDIATELY UPON PUBLICATION 